\title{
"An extension of the Expectation Confirmation Model (ECM) to study continuance behavior in using e-Health services"
}

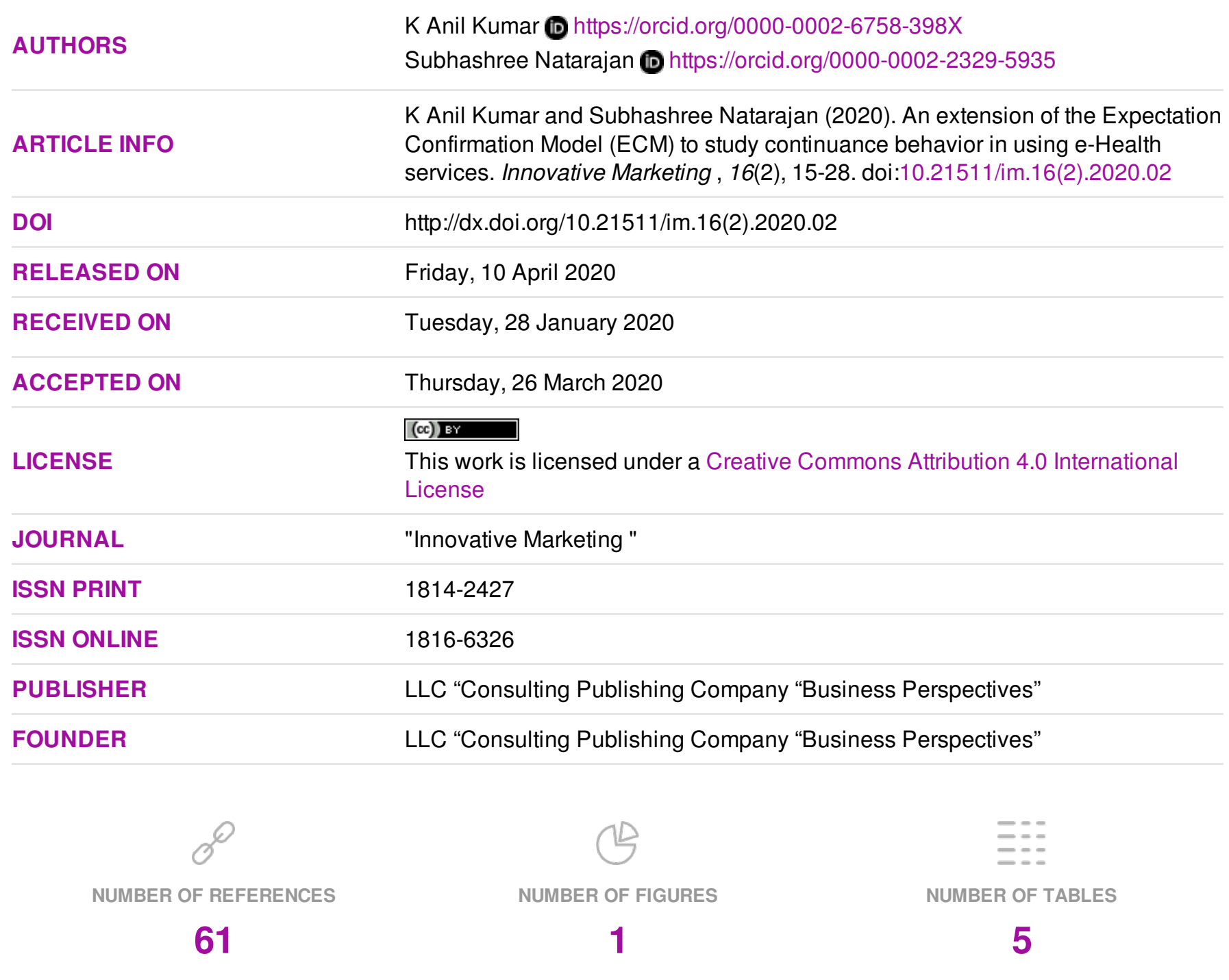

(C) The author(s) 2023. This publication is an open access article. 


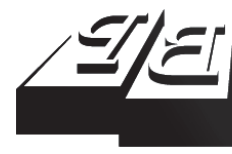

\section{BUSINESS PERSPECTIVES}

(2)

LLC "CPC "Business Perspectives"

Hryhorii Skovoroda lane, 10, Sumy, 40022, Ukraine

www.businessperspectives.org
Received on: $28^{\text {th }}$ of January, 2020 Accepted on: $26^{\text {th }}$ of March, 2020 Published on: $10^{\text {th }}$ of April,2020

(c) K Anil Kumar, Subhashree Natarajan, 2020

K Anil Kumar, Ph.D. Candidate, Teaching cum Research Assistant, VIT Business School, Vellore Institute of Technology, India.

Subhashree Natarajan, Professor, Dean, VIT Business School, Vellore Institute of Technology, India.

\section{AN EXTENSION OF THE EXPECTATION CONFIRMATION MODEL (ECM) TO STUDY CONTINUANCE BEHAVIOR IN USING E-HEALTH SERVICES}

\begin{abstract}
Given the negative utilitarianism and difficulty in maintaining long-term loyalty, hospitals resort to a variety of images that define and redefine their relationship strategies in order to stay patient-centric. As in any other sector, in healthcare, patients play an important role in service design and delivery. The basic services of medical appointment scheduling, online payment and health information search are recognized as one of the most important elements that increase patient footfall, service planning, patient satisfaction and their continued usage, in particular in developing economies such as India. This study seeks to understanding the basic e-Health services continuance usage intention among patients by integrating the Expectation Confirmation Model (ECM) and the Technology Acceptance Model (TAM) and extending them by including certain external variables. With a well-structured questionnaire, a survey of 453 respondents - out-patients and care-givers, who should have used e-Health services at least once, in particular, visited multispecialty hospitals, revealed that along with the ECM and TAM constructs such as satisfaction, confirmation, perceived ease-of-use, and perceived usefulness, the external variables such as trust, social influence, perceived service quality, and perceived privacy and security had a significant influence $(\mathrm{p}<0.05)$ on e-Health services continuance usage. The main findings of the study contribute to developing and empirically testing a model that explains the basic process of motivating the e-Health service users for continuance usage intention.
\end{abstract}

\section{Keywords}

\section{healthcare, patients, technology acceptance model,} developing countries, trust, privacy and security

\section{JEL Classification M31, I12}

\section{INTRODUCTION}

Healthcare sector, in emerging economies like India- where health rate is poor, potential is more and technological advancements are faster, hospitals competitively seek newer avenues to deliver new, effective and efficient healthcare services (Martínez-Caro, Cegarra-Navarro, \& Solano-Lorente, 2013). Emergence of internet technologies has made health care sector dynamic in providing in-person and remote services, Emami (2017) defines "e-health is an emerging field in the intersection of medical informatics, public health and business, referring to health services and information delivered or enhanced through the Internet and related technologies". However, e-Health is a broader field that includes digitalization of several tasks and processes of healthcare, which also includes use of internet to store, access, and modify healthcare information, resulting in new terms such as e-records, e-prescription, e-payment, e-billing and e-appointments. In healthcare sector, it is extensively acknowledged that the use of internet technologies has offered a great potential for reducing organizational expenses, improving effectiveness and efficiency of the personnel, 
and enhancing quality of services provided (Davis, Bagozzi, \& Warshaw, 1989; Ramprasad, Tamariz, Garcia-Barcena, Nemeth, \& Palacio, 2019). The applications of internet technologies in this sector are numerous. This study pertains to e-Health services (online healthcare services) offered by private hospitals in India, to their customers, such as making a doctor's appointment; hospital payment transactions; and health related information search. Due to competitive pressures and customer expectations, private sector hospitals have shown keen interest in establishing continued services with improved standards in offering effective services to their customers. These services are considered as a basic e-services in hospitals, which are more felicitous to healthcare end-users (e.g., patients and care-givers) as these services are more and easily accessible, requires less effort, and saves their time (Martinez-Caro et al., 2013). Altogether, the usage of e-Health services results in achieving better patient satisfaction and cost-savings (Campanella, Serino, Mustilli, Crisci, \& D’Ambra, 2020).

However, the introduction of these e-services is effective only when the end-users use these e-Health services on a regular basis. Yet, these services inherit huge investment and risk of rejection by customers. According to many authors, the continuance usage is significant due to the following reasons: (a) Non-acceptance of e-health services (adoption and post-adoption), would lead to huge financial / resource losses for the hospitals (Boyce, Browne, \& Greenhalgh, 2014); (b) Though the consumers adopt the e-services, the technological developments compel hospitals to continuously upgrade for sustained continuance usage (Zhang, Lu, Gupta, \& Gao, 2015).

It has become essential for the healthcare sector to identify and understand the requirement of the patients to sustain in the competitive market. In the marketing literature, considerable research has been carried out in understanding the key factors that impact and drive practitioners to use e-Health services (Furusa \& Coleman, 2018). Though the e-Health services are highly helping the people to effectively manage their health, the use of these technologies often lasts only for a short span of time. Since e-Health services is a booming phenomenon, there is still not a clear picture about the post-adoption behavior i.e., continuance usage intention. This sheds light on the requirement to delve more deeply on e-Health services post adoption behavior. In addition, the study of Wang, Liu, Gao, and Zhang (2020) states that there is an insufficiency of study that recommends pertinent factors influencing patients' satisfaction towards technology usage in high credence services like healthcare. Therefore, this study focuses on exploring the psychological mechanism that determines the e-Health services continuance usage intention through application of technology acceptance model (TAM) and expectation-confirmation model (ECM). TAM model explains on the factors that make the users' to adopt the technology and ECM model relies on explaining the post adoption behavior i.e., continuance usage intention of e-Health services.

\section{LITERATURE REVIEW AND HYPOTHESES DEVELOPMENT}

\subsection{Research on e-health services}

Along with the introduction of information and communication technologies in the health sector, e-Health services are becoming an increasingly relevant research topic. Healthcare encompasses medical equipment, health insurance, medical tourism, telemedicine, outsourcing, medical devices, and hospitals. E-Health ser- vices include appointment scheduling, health information search, online payment, telemedicine, electronic health records, etc. Although health systems in developing countries strive to provide easy access to healthcare services, there are barriers even in the adoption of the basic services such as medical appointment scheduling and online payment (Varshney, 2009; Goh et al., 2011). These basic services are recognized as one of the most important elements that increase patient footfall, contribute to effective service planning, and enhance patient satisfaction and their continued usage of e-services (Varshney, 2009). 
Empirical research review initially emphasized the need to study the factors that facilitate the users' adoption and continuance usage of the basic e-Health services (Cho, Quinlan, Park, \& Noh, 2014). Later, it was asserted that the factors influencing the technology adoption behavior through motivational theories include theory of planned behavior, technology acceptance model, theory of reasoned action and theory of diffusion and innovation. Nevertheless, the factors influencing technology acceptance behavior and its continuance usage varied across developing and developed countries. With respect to developed countries, several studies identified that factors, such as personal factors, technology characteristics, organizational characteristics, and characteristics of external environment, influence the acceptance and usage behavior (Kim \& Park, 2012). Similarly, studies in developing countries explored the factors of the initial acceptance of e-Health services using the Technology Acceptance Model (Lee \& Chen, 2014). However, there is very little research to identify the factors affecting the continuance usage of basic e-Health services (Cho, 2016). To fully comprehend the ease of access of e-Health services, it is necessary to identify the factors influencing the continuance usage behavior. Due to this need to identify the post-adoption behavior (continuance usage behavior), this research explores the factors determining CUI of patients in adopting the basic e-Health services in India.

\subsection{Theoretical background}

\subsubsection{Continuance intention with the Post-Acceptance Model (PAM)}

Bhattacherjee (2001) proposed a distinguished Post Adoption Model (PAM) to improve continuance usage by synthesizing the components of TAM (initial adoption behavior) and ECT (post-purchase behavior) (see Figure 1). Specifically, PAM includes key ECT components, namely confirmation and satisfaction, as factors that determine continuance usage behavior. Therefore, confirming the IS (information system) by individuals with their initial expectations (by experience) leads to their satisfaction. Thus, the PAM theory proposed by Bhattacherjee justifies the relevance of confirmation and satisfaction in explaining the CUI of adopted IS. Besides, PAM relies on TAM to explain the logic behind continuance intention. According to Davis, Bagozzi, and Warshaw (1989), individual behavior on initial adoption depends on two major factors: First, perceived usefulness $(\mathrm{PU})$, which states that "the extent an individual believes in using a specific technology/system improves their related performance" (Kim \& Park, 2012). Second, the perceived ease-of-use (PEOU), which emphasizes, that the usage of a specific system/technology will be free of effort. Of these two factors, Bhattacherjee (2001) initially focused only on perceived usefulness (PU) in determining the behavior of an individual. Following this base of PAM, rigorous research in continuance behavior is further explored. Among which, the recent study by Cho, Quinlan, Park, and Noh (2016) proved the importance of PEOU as another factor and extended the PAM model with PEOU in the health care context.

The logic behind considering both of the TAM constructs (PU and PEOU) is because an individual believes that the technology adopted enhances his/her job performance, then PU increases. Subsequently, if the technology manages the work to be done effortlessly, then PEOU plays a significant role in adopting and CUI. In addition, to extend ECM, the TAM model is considered, as it is the preferred model over other behavioral intention models such as the Theory of Planned Behavior (TPB) and the Theory of a Reasoned Action (TRA). In addition, substantial theoretical and empirical support has accumulated in favor of TAM, compared to other models (Chuah, Rauschnabel, Krey, Nguyen, Ramayah, \& Lade, 2016). Some of the studies have discreetly anticipated that continued usage is an extension of adoption and used TAM in explaining the continuance usage situations (Cheng, 2020; Kumar \& Natarajan, 2019). Hayashi, Chen, Ryan, and $\mathrm{Wu}(2020)$ have stated that ECM and TAM are conceptually very similar, and integrating these models will enhance the predictive power.

\subsubsection{Extended Post-Acceptance Model (EECM) with factors}

Although the original PAM was extended and tested with PEOU, as it is an important factor in determining CUI (Thong, Hong, \& Tam, 2006), however, scientific studies have emphasized the 
importance of TAM constructs with other factors in continuance usage, since the factors were found to vary depending on context. For instance, ECM was extended with personal innovativeness in the context of mobile commerce (Hung, Hwang, \& Hsieh, 2007), perceived enjoyment was included in digital learning (Joo, Park, \& Shin, 2017), and habits, subjective norms and enjoyment were integrated in social networking sites (Mouakket, 2015). But, given the negative utilitarian sector, such as healthcare, studies demand to explore the unique factors influencing its continuance usage (Mettler, 2012). Susanto, Chang, and Ha (2016) underline security concerns as a major determinant of usage intention in banking and hospital sectors. Also, the result of meta-analysis conducted by Chauhan and Jaiswal (2017) in developed countries highlights service quality (Akter, D'Ambra, \& Ray, 2013), individual belief and norms and security concerns (Susanto, Chang, \& Ha, 2016 ) as the major factors that contribute to greater vari- ance in continuance behavior of e-Health services. Therefore, based on the previous findings on continuance usage research, the current study extended the post acceptance model by identifying trust, security and privacy, perceived service quality, and social influence as the main influential factors in determining CUI of e-Health services.

\subsection{Research framework and hypotheses development}

The proposed research model (see Figure 1) is developed by integrating ECM and TAM models with four external constructs that reflect CUI of e-Health services.

\subsubsection{Expectation Confirmation Model}

The Expectation Confirmation Model (ECM) proposed by Bhattacherjee (2001) is used as a fundamental principle for this study. In market-

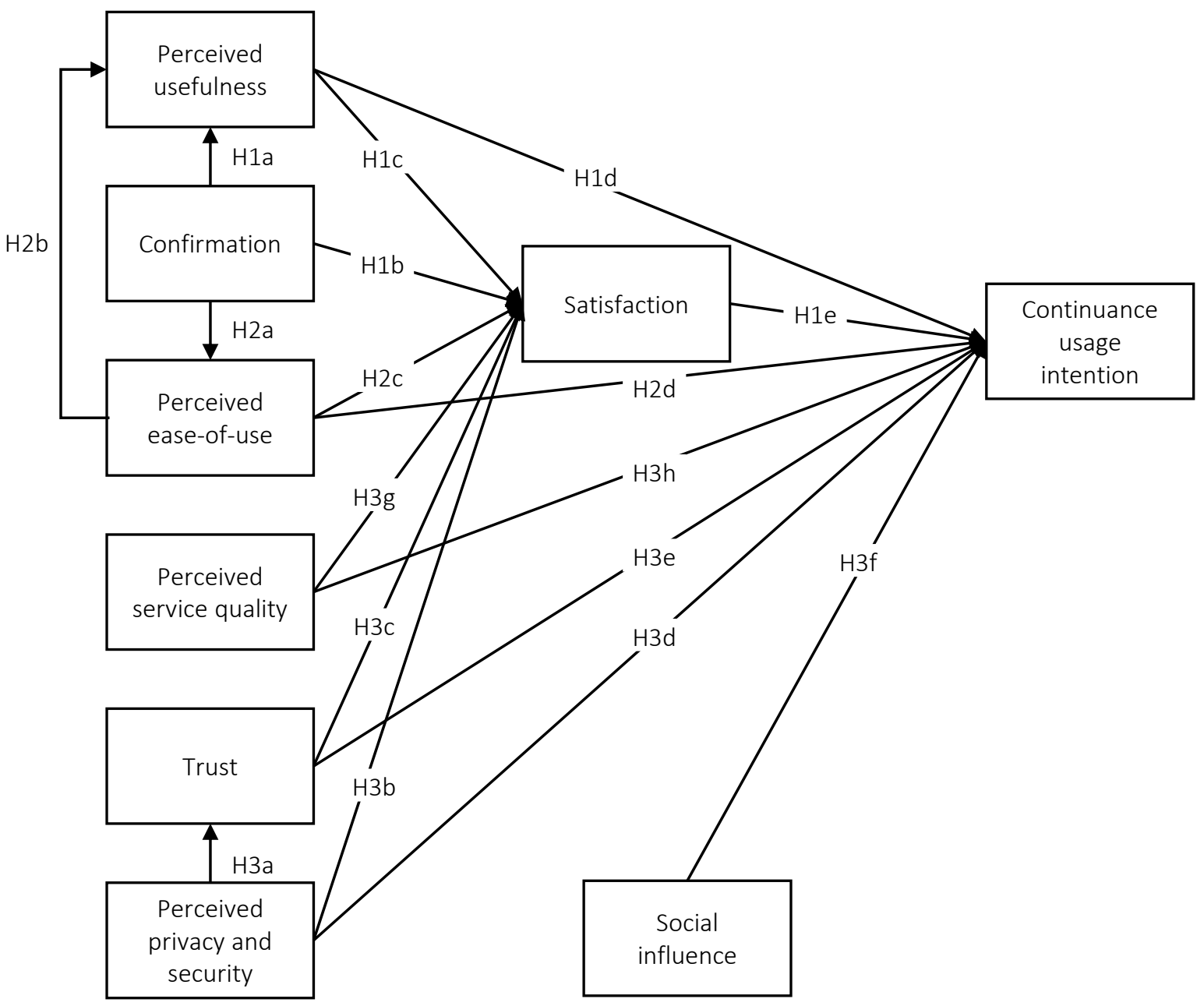

Figure 1. Research framework of the study 
ing, according to Oliver (1993), when users are satisfied with the ICT usage, they most likely intend to use ICT continuously. User satisfaction refers to the complete assessment of ICT that replicates the emotion-based response based on specified technologies (Kim, 2010). Prior studies have empirically proved that user satisfaction is the critical source for ICT CUI (Thong, Hong, \& Tam, 2006; Kim, 2010). Earlier studies have claimed that post-adoption expectation is based on 'PU', which is an extrinsic motivation, and when users' expectations are more than or up to the level of expectations they pretend to be satisfied, this results in CUI (Zhang, Gupta, \& Gao, 2015). Thus, based on theoretical and literature evidence, following hypotheses are put forward:

H1a: Confirmation will have a positive influence on PU of e-Health services.

H1b: Confirmation will have a positive influence on satisfaction with e-Health services.

H1c: PU will have a positive influence on satisfaction with e-Health services.

H1d: PU will have a positive influence on CUI for $e$-Health services.

H1e: Satisfaction will have a positive influence on CUI for e-Health services.

\subsubsection{Technology Acceptance Model}

A number of studies have endeavored to build and empirically test the models of continued information technology usage behavior (Premkumar \& Bhattacherjee, 2008). This study attempts to augment the understanding of behavioral intention in continuous IT usage. Even though TAM and ECM emphasize various viewpoints on user perceptions, the integration of these theories will result in better understanding of adoption and continuance usage behavioral intention. Prior studies have also evidenced that the synthesized model will provide a comprehensive knowledge on the ICT phenomenon (Wang, 2016; Hou, 2015). Henceforth, the integration will help bridge the gap between acceptance and continued influx of research on behavioral intention system usage.
Cho (2016) extended the Bhattacherjee's (2001) model by integrating TAM and ECM. Provided with plenty of support for positive influence of $\mathrm{PU}$ based on existing TAM research, PEOU is counted in ECM. TAM supports that 'PEOU' is strongly correlated with 'PU'. The theory by itself provides an evidence that, individual behavioral intention is been significantly affected by 'PEOU' and 'PU' indirectly through the 'attitude' of an individual. In addition, the extended model of Cho (2016) has shown a positive relationship between 'confirmation' and 'PEOU'. TAM has been applied expansively to user acceptance research of several types of technologies comprising telemedicine, electronic personal health records, electronic medical records, mobile healthcare, and e-government (Kim \& Park, 2012). Thus the following hypotheses are posited:

H2a: Confirmation will have a positive influence on PEOU for e-Health services.

H2b: PEOU will have a positive influence on $P U$ of e-Health services.

H2c: PEOU will have a positive influence on satisfaction with e-Health services.

H2d: PEOU will have a positive influence on CUI for e-Health services.

\subsubsection{Perceived privacy and security (PPS), trust, perceived service quality (PSQ), and social influence on continuance usage intention (CUI)}

PPS reflects user concerns regarding information disclosure. IT development takes into account the need for information processing, and its complexity has led to the fact that privacy has become a critical issue. This fact undermines the consumer confidence in service providers, as consumers worry about shared personal information (Casaló, Flavián, \& Guinalíu, 2007). Akter, D’Ambra, and Ray (2013) stated that information security and privacy include the collection, improper access, errors, and unauthorized use of secondary data. When service providers gain the trust of users, the usage of e-services becomes continued, which indicates the positive consumer attitudes towards service providers (Chang \& Chen, 2009). 
Trust empowers users to accept the fact that service providers have the potential, benevolence, integrity and ability to protect the provided information from potential misuse and risk. Trust acts as a subjective guarantee to the consumers to achieve the good experience in the present and in the future (Akter, D’Ambra, \& Ray, 2013). According to Zhou and Li (2014), trust is a facilitator for CUI and indirectly results in continued usage through satisfaction. When the users' PPS and trust towards the usage of certain technology is greater, this directly leads to satisfaction and, therefore, to CUI (Mou \& Cohen, 2017).

In the service industry, PSQ is one of the most significant predictors for services usage. According to Parasuraman, Zeithaml, and Berry (1985), PSQ captures the difference between actual performance and system expectations for quality dimensions. Earlier studies have proven that PSQ is a key component of the healthcare industry and a vital antecedent for satisfaction. Oghuma, Libaque-Saenz, Wong, and Chang (2016) have shown a positive impact of confirmation on PSQ, and that user satisfaction is affected by overall confirmation of their use experience.

Social influence, or subjective norm, plays a vital role in decision-making and human behavior. Earlier studies focused on the impact of subjective norms on technology acceptance, and their outcomes varied. Mathieson (1991) and Davis, Bagozzi, and Warshaw (1989) found a weak relationship between social influence and other variables, whereas Moore and Benbasat (1991) revealed a stronger association.

Nevertheless, subjective norm was found to have no direct effect on technology acceptance in the context of healthcare. But the theoretical notion of TPB highlights the significant association. In addition, Aggelidis and Chatzoglou (2009) have found a positive effect of social influence on CUI among physicians in HIS (Hospital Information System) usage. Thus the following hypotheses are proposed:

H3a: PPS will have a positive influence on trust in $e$-Health services.

H3b: PPS will have a positive influence on satisfaction with e-Health services.
H3c: Trust will have a positive influence on satisfaction with e-Health services.

H3d: PPS will have a positive influence on CUI for $e$-Health services.

H3e: Trust will have a positive influence on CUI for e-Health services.

H3f: Social influence will have a positive effect on CUI for e-Health services.

H3g: PSQ will have a positive influence on satisfaction with e-Health services.

H3h: PSQ will have a positive influence on CUI for $e$-Health services.

\section{METHODS}

\subsection{Instruments}

The items to measure the constructs have been adopted from the extant literature to ensure the content validity. To ensure face validity, the items were evaluated by experts in this field. To measure the main study variables, multiple scales have been used. The Likert-type five-point scale, ranging from 1 being 'strongly disagree' to 5 being 'strongly agree', is used to measure the variables. To evaluate 'PU' and 'PEOU, the measures were adopted from Chang, Pang, Tarn, Liu, and Yen (2015) with four items respectively. To measure 'PPS', the items were adopted from Hoque (2016) with six items. 'Perceived trust' was measured using the items adopted from Chen, Liu, and Lin (2013) with four items. To determine 'confirmation,' 'satisfaction' and 'CUI,' the items were adopted from Paré, Trudel, and Forget (2014) and Chen, Liu, and Lin (2013) with four items, three items and four items, respectively. 'Social influence' was deliberated from Aggelidis and Chatzoglou (2009), with four items. 'PSQ' consists of four items adopted from Chang, Liu, and Chen (2014).

\subsection{Data collection}

Since the study focuses on the healthcare sector and the customer perspective, the sample units chosen for this study are hospital customers out-patients and care-givers, who should have 
used e-Health services at least once, in particular, patients visiting multispecialty hospitals in the state of Tamil Nadu; that represents the diverse population of India. The geographical location chosen for the data collection is Chennai, as it is among the five top metropolitan areas in India, where the technology usage is larger in number according to the joint research report by Google and Forrester (2017). The Hospitals in India, 2017 report states that South Indian hospitals are well equipped and managed by highly skilled professionals; among which Tamil Nadu has a lot of private and public hospitals authorized by the Indian government. For the purpose of the study, it is also ensured that the chosen four multispecialty hospitals in Chennai provide e-Health services to their customers.

This study used a purposive sampling method because it is difficult to estimate the precise population size of the patients procuring the treatment or the other users (care-givers) who use e-Health services in India. The data were personally collected when visiting hospitals from 453 valid samples using a well-structured closed ended questionnaire, resulting in 82.4 percent acceptance rate. The sample size of 453 satisfies the subject-to-item ratio as recommended by Hair, Hult, Ringle, and Sarstedt (2016). The sample size also satisfies the thumb rule of SEM (Structural Equation Model), where the minimum number of sample size must be greater than 200 samples (Kline, 2011), and a thumb rule of SmartPLS SEM, where the sample size should be 10 times greater than the highest number of measurement items for a specified construct in the instrument (Hair, Hult, Ringle, \& Sarstedt, 2016).
Table 1 shows the demographic profile of the survey respondents. The gender distribution of the respondents has been balanced, with 53.2 percent of males and 46.8 percent of females. Besides, 37.7 percent of the respondents are between the ages 29 to 36 , and 41.9 percent completed postgraduate education.

Among the respondents, 48.8 percent use e-Health services for the benefit of their family members, while 32.9 percent use for themselves and 18.3 percent access e-Health services for their friends. Table 2 shows the correlation coefficient " $r$ " that lies between 0.3 and 0.8 , which indicates a significant positive linear relationship among the variables. These results provided preliminary support for the proposed research hypotheses.

\section{RESULTS}

Before testing the model, the data were checked for normality using the Shapiro-Wilk test, which gave a significant result. Further, the sampling adequacy was entrenched using Kaiser-MeyerOlkin (KMO) and Bartlett's test Sphericity tests that showed positive sampling adequacy (KMO: 0.898; Bartlett's test: significant at 0.00). To test the research model, Partial Least Squares (PLS) were used, as this technique has several advantages. First, SEM (Structural Equation Modeling) as a second-generation technique, can analyze indicator loadings (and weights) on constructs (hence, measuring construct validity) and estimate casual relationships with constructs in multistage models (Sarstedt, Ringle, \& Hair, 2017). Second, PLS is the robust co-variance based modeling for theory

Table 1. Demographic profile of respondents

\begin{tabular}{|c|c|c|c|}
\hline \multicolumn{2}{|c|}{ Demographic variables } & \multirow{2}{*}{$\frac{\text { Number of respondents }}{241}$} & \multirow{2}{*}{$\frac{\text { Percentage }}{53.2}$} \\
\hline Gondor & Male & & \\
\hline Gertue! & Female & 212 & 46.8 \\
\hline \multirow{3}{*}{ Age } & $20-28$ & 145 & 32.0 \\
\hline & $>28-36$ & 171 & 37.7 \\
\hline & Above 36 & 137 & 30.2 \\
\hline \multirow{4}{*}{ Education } & School level & 19 & 04.1 \\
\hline & UG & 165 & 36.4 \\
\hline & PG & 190 & 41.9 \\
\hline & Others & 79 & 17.4 \\
\hline \multirow{3}{*}{ For whom e-services are available } & Myself & 149 & 32.9 \\
\hline & Family member & 221 & 48.8 \\
\hline & My friend & 83 & 18.3 \\
\hline
\end{tabular}


Table 2. Correlation among study variables

\begin{tabular}{|c|c|c|c|c|c|c|c|c|c|}
\hline Constructs & PU & PEOU & TR & PPS & SI & PSQ & CNF & STF & CUI \\
\hline PU & 1 & - & - & - & - & - & - & - & - \\
\hline PEOU & $.528^{*}$ & 1 & - & - & - & - & - & - & - \\
\hline TR & $.518^{*}$ & $.430^{*}$ & 1 & - & - & - & - & - & - \\
\hline PPS & $.527^{*}$ & $.520^{*}$ & $.585^{*}$ & 1 & - & - & - & - & - \\
\hline SI & $.363^{*}$ & $.360^{*}$ & $.435^{*}$ & $.663^{*}$ & 1 & - & - & - & - \\
\hline PSQ & $.716^{*}$ & $.394^{*}$ & $.511^{*}$ & $.639^{*}$ & $.550^{*}$ & 1 & - & - & \\
\hline CNF & $.309^{*}$ & $.671^{*}$ & $.369^{*}$ & $.577^{*}$ & $.426^{*}$ & $.479^{*}$ & 1 & - & - \\
\hline STF & $.382^{*}$ & $.357^{*}$ & $.825^{*}$ & $.636^{*}$ & $.523^{*}$ & $.508^{*}$ & $.466^{*}$ & 1 & - \\
\hline CUI & $.484^{*}$ & $.486^{*}$ & $.549^{*}$ & $.709^{*}$ & $.630^{*}$ & $.630^{*}$ & $.559^{*}$ & $.614^{*}$ & 1 \\
\hline
\end{tabular}

Note: $* *$ Correlation is significant at the 0.01 level (2-tailed), $N=453$.

testing, which is appropriate for this study Further, with regard to the final estimates, PLS provides better approximation (Hair, Hollingsworth, Randolph, \& Chong, 2017).

Therefore, PLS was opted to test the research model of this study. The data were analyzed in two phases (a measurement model and a structural model). First, the establishment of reliability and validity confirms the measurement model. Consequently, with the structural model, the study hypotheses were tested.

\subsection{Measurement model}

To assess the instrument reliability and validity, a nine-factor measurement model was set-up under the CFA (confirmatory factor analysis) approach. To load the items on their pre-specified factors, each item was restricted, while the factors oneself were permitted to correlate freely. Tables 3 and 4 show CFA results.

Table 3. Confirmatory factor analysis results

\begin{tabular}{|c|c|c|c|c|c|}
\hline Construct & Item & $\begin{array}{l}\text { Standard } \\
\text { loading* }\end{array}$ & AVE & CR & $\alpha$ \\
\hline \multirow{4}{*}{$\begin{array}{l}\text { Perceived } \\
\text { usefulness }\end{array}$} & $P \cup 1$ & .705 & 0.794 & 0.921 & 0.903 \\
\hline & PU2 & .825 & - & - & - \\
\hline & PU3 & .777 & - & - & - \\
\hline & PU4 & .718 & - & - & - \\
\hline \multirow{4}{*}{ Confirmation } & CON1 & .884 & 0.760 & 0.884 & 0.917 \\
\hline & CON2 & .900 & - & - & - \\
\hline & CON3 & .904 & - & - & - \\
\hline & CON4 & .856 & - & - & - \\
\hline \multirow{4}{*}{$\begin{array}{l}\text { Perceived } \\
\text { ease-of-use }\end{array}$} & PEOU1 & .788 & 0.748 & 0.922 & 0.887 \\
\hline & PEOU2 & .754 & - & - & - \\
\hline & PEOU3 & .777 & - & - & - \\
\hline & PEOU4 & .799 & - & - & - \\
\hline \multirow{4}{*}{$\begin{array}{l}\text { Perceived } \\
\text { service quality }\end{array}$} & PSQ1 & .789 & 0.759 & 0.886 & 0.891 \\
\hline & PSQ2 & .764 & - & - & - \\
\hline & PSQ3 & .790 & - & - & - \\
\hline & PSQ4 & .795 & - & - & - \\
\hline
\end{tabular}

\begin{tabular}{|c|c|c|c|c|c|}
\hline Construct & Item & $\begin{array}{l}\text { Standard } \\
\text { loading* }\end{array}$ & AVE & CR & $\alpha$ \\
\hline \multirow{6}{*}{$\begin{array}{l}\text { Perceived } \\
\text { privacy and } \\
\text { security }\end{array}$} & PPS1 & .803 & 0.807 & 0.926 & 0.916 \\
\hline & PPS2 & .844 & - & - & - \\
\hline & PPS3 & .859 & - & - & - \\
\hline & PPS4 & .829 & - & - & - \\
\hline & PPS5 & .782 & - & - & - \\
\hline & PPS6 & .793 & - & - & - \\
\hline \multirow{4}{*}{$\begin{array}{l}\text { Social } \\
\text { influence }\end{array}$} & SI1 & .785 & 0.731 & 0.916 & 0.915 \\
\hline & $\mathrm{SI} 2$ & .776 & - & - & - \\
\hline & $\mathrm{SI3}$ & .810 & - & - & - \\
\hline & $\mathrm{SI}$ & .806 & - & - & - \\
\hline \multirow{4}{*}{ Trust } & TR1 & .887 & 0.807 & 0.926 & 0.880 \\
\hline & TR2 & .821 & - & - & - \\
\hline & TR3 & .865 & - & - & - \\
\hline & TR4 & .836 & - & - & - \\
\hline \multirow{3}{*}{ Satisfaction } & STF1 & .851 & 0.814 & 0.929 & 0.912 \\
\hline & STF2 & .867 & - & - & - \\
\hline & STF3 & .845 & - & - & - \\
\hline \multirow{4}{*}{$\begin{array}{l}\text { Continuance } \\
\text { usage intention }\end{array}$} & CUI1 & .816 & 0.781 & 0.914 & 0.883 \\
\hline & CUI2 & .877 & - & - & - \\
\hline & CUI3 & .833 & - & - & - \\
\hline & CUI4 & .820 & - & - & - \\
\hline
\end{tabular}

Note: * All standard loadings are significant at $p<0.001$.

Table 3 shows that the value of composite reliability and Cronbach's alpha of each construct ranges from 0.880 to 0.929 , which is greater than the suggested threshold of 0.7 (Hair, Hollingsworth, Randolph, \& Chong, 2017), thus demonstrating the reliability satisfactory level. The discriminant validity and convergent validity were tested to ensure the construct validity. AVE (Average Variance Extracted) and indicator loadings were examined to test the convergent validity. All the resulted values of AVE were above the desired threshold of minimum 0.5 (Fornell \& Larcker, 1981). To ensure the convergent validity, all the standard loadings were inspected, which led to exceeding the recommended value of 0.6 and significance at 0.001 (Fornell \& Larcker, 1981). 
Table 4. Discriminant analysis

\begin{tabular}{|c|c|c|c|c|c|c|c|c|c|}
\hline Constructs & CON & CUI & PEOU & PSQ & STF & PPS & SI & TR & PU \\
\hline $\mathrm{CON}$ & 0.855 & - & - & - & - & - & - & - & - \\
\hline CUI & $0.153^{*}$ & 0.902 & - & - & - & - & - & - & \\
\hline PEOU & $0.659^{*}$ & $0.307^{*}$ & 0.884 & - & - & - & - & - & - \\
\hline PSQ & $0.400^{*}$ & $0.163^{*}$ & $0.382^{*}$ & 0.812 & - & - & - & - & - \\
\hline STF & $0.362 *$ & $0.161^{*}$ & $0.368^{*}$ & $0.412 *$ & 0.812 & - & - & - & - \\
\hline PPS & $0.571^{*}$ & $0.139 *$ & $0.542 *$ & $0.372 *$ & $0.309 *$ & 0.865 & - & - & - \\
\hline $\mathrm{SI}$ & $0.348^{*}$ & $0.567^{*}$ & $0.457^{*}$ & $0.196 *$ & $0.205^{*}$ & $0.280 *$ & 0.821 & - & - \\
\hline TR & $0.691^{*}$ & $0.199 *$ & $0.638^{*}$ & $0.295^{*}$ & $0.209 *$ & $0.573^{*}$ & $0.310^{*}$ & 0.898 & - \\
\hline $\mathrm{PU}$ & $0.669^{*}$ & $0.214^{*}$ & $0.715^{*}$ & $0.339 *$ & $0.296^{*}$ & $0.594^{*}$ & $0.408^{*}$ & $0.604^{*}$ & 0.877 \\
\hline
\end{tabular}

Note: ${ }^{*} p<0.05 ;{ }^{* *} p<0.01 ; * * *<0.001 ;$ CON-confirmation; CUI- continuance usage intention; PEOU-perceived ease-ofuse; PSQ- perceived service quality; STF- satisfaction; PPS- perceived privacy and security; SI- social influence; TR- trust; PUperceived usefulness

To ascertain the discriminant validity, square roots of AVEs should be greater than the inter-construct correlations portrayed in the off-diagonal entries (Hair, Hollingsworth, Randolph, \& Chong, 2017), signifying the acceptability of discriminant validity (as shown in Table 4).

\subsection{Structural model}

Table 5 shows the Smart PLS path coefficients. The value of t-statistics is found to be greater than 1.96 for all the paths. Confirmation has a significant effect on perceived usefulness, positively influencing satisfaction and CUI, while it is significant towards satisfaction, which in turn has a positive effect on CUI of e-Health services. Thus, H1a, H1b, H1c, H1d and H1e were supported.
In terms of PEOU, confirmation had a significant effect on ease-of-use, and PEOU had a positive effect on PU, satisfaction, and CUI, thus supporting $\mathrm{H} 2 a, \mathrm{H} 2 \mathrm{~b}, \mathrm{H} 2 \mathrm{c}$ and $\mathrm{H} 2 \mathrm{~d}$. The effect of PPS on trust, satisfaction and CUI, and the effect of trust on satisfaction and continuance intention are significant. Thus $\mathrm{H} 3 a, \mathrm{H} 3 \mathrm{~b}, \mathrm{H} 3 \mathrm{c}$, $H 3 d$ and H3e were supported. The effect of social influence on the usage intention is positive, resulting in acceptance of hypothesis $H 3 f$. In addition, PSQ has a significant effect on satisfaction and CUI, thus hypotheses $\mathrm{H} 3 \mathrm{~g}$ and $\mathrm{H} 3 \mathrm{~h}$ are supported. The explanatory power $\left(R^{2}\right)$ of CUI is 0.704 , which is considered to have better explanatory power (Hair, Ringle, \& Sarstedt, 2013).

Table 5. Structural path coefficients

\begin{tabular}{|c|c|c|c|c|c|c|c|c|}
\hline Hypotheses & $\begin{array}{l}\text { Original } \\
\text { sample }\end{array}$ & $\begin{array}{l}\text { Sample } \\
\text { mean }\end{array}$ & $\begin{array}{l}\text { Standard } \\
\text { deviation }\end{array}$ & Beta & $T$-statistics & $P$-value & Sig. & Results \\
\hline $\mathrm{H} 1 \mathrm{a}$ & 0.365 & 0.363 & 0.036 & 0.362 & 10.083 & 0.000 & Yes & Accepted \\
\hline$H 1 b$ & 0.576 & 0.586 & 0.043 & 0.658 & 15.303 & 0.001 & Yes & Accepted \\
\hline $\mathrm{H} 1 \mathrm{C}$ & 0.270 & 0.274 & 0.050 & 0.269 & 5.383 & 0.000 & Yes & Accepted \\
\hline H1d & 0.458 & 0.455 & 0.062 & 0.459 & 7.414 & 0.000 & Yes & Accepted \\
\hline H1e & 0.152 & 0.151 & 0.066 & 0.152 & 2.314 & 0.021 & Yes & Accepted \\
\hline $\mathrm{H} 2 \mathrm{a}$ & 0.436 & 0.444 & 0.045 & 0.440 & 9.799 & 0.000 & Yes & Accepted \\
\hline $\mathrm{H} 2 \mathrm{~b}$ & 0.539 & 0.541 & 0.044 & 0.556 & 12.652 & 0.000 & Yes & Accepted \\
\hline $\mathrm{H} 2 \mathrm{C}$ & 0.134 & 0.135 & 0.038 & 0.132 & 3.474 & 0.001 & Yes & Accepted \\
\hline$H 2 d$ & 0.106 & 0.107 & 0.043 & 0.105 & 2.451 & 0.015 & Yes & Accepted \\
\hline $\mathrm{H} 3 \mathrm{a}$ & 0.387 & 0.385 & 0.040 & 0.391 & 9.777 & 0.034 & Yes & Accepted \\
\hline$H 3 b$ & 0.134 & 0.131 & 0.042 & 0.133 & 3.181 & 0.002 & Yes & Accepted \\
\hline $\mathrm{H} 3 \mathrm{c}$ & 0.224 & 0.222 & 0.029 & 0.220 & 7.618 & 0.000 & Yes & Accepted \\
\hline$H 3 d$ & 0.107 & 0.109 & 0.053 & 0.107 & 2.027 & 0.000 & Yes & Accepted \\
\hline H3e & 0.145 & 0.145 & 0.041 & 0.144 & 3.517 & 0.001 & Yes & Accepted \\
\hline H3f & 0.182 & 0.183 & 0.036 & 0.182 & 5.074 & 0.000 & Yes & Accepted \\
\hline $\mathrm{H} 3 \mathrm{~g}$ & 0.236 & 0.235 & 0.043 & 0.238 & 5.557 & 0.000 & Yes & Accepted \\
\hline $\mathrm{H} 3 \mathrm{~h}$ & 0.125 & 0.124 & 0.045 & 0.124 & 2.757 & 0.006 & Yes & Accepted \\
\hline
\end{tabular}

Note: $p$-value $<0.000-$ significant at $1 \%$ level; $p$-value $<0.05-$ significant at $5 \%$ level. 


\section{DISCUSSION}

The main objective of this study is to identify the factors that influence CUI of e-Health services among healthcare customers (patients and care-givers). Based theoretically on ECM and TAM, this study has tested multiple hypotheses related between the key components of these theories and some external variables. The main results of this study supported all the proposed hypotheses. In support of previous studies (Cho, 2016; Bhattacherjee, 2001), confirmation, as a post-consumption perception, both directly and indirectly influences satisfaction and CUI of consumers through their perceptions such as PEOU and PU in using the services in general and e-Health services in particular. The study results also revealed that PPS impacts trust and user satisfaction. Health literature and other sources have highlighted the irrefutable role of PPS in building trust (Susanto, Chang, \& Ha, 2016; Casaló, Flavián, \& Guinalíu, 2007). Since e-Health involves sharing of personal and sensitive information, it is captious to pledge users that the usage of e-Health services is secured. Only when hospitals achieve a high level of patient confidence in security and privacy do users trust hospitals and use e-Health services continuously.

The significant relationship between user satisfaction and PPS is in line with the expectation. All user categories, highly experienced or less experienced users, expect hospitals to provide privacy and security protection of the provided personal information (Susanto, Chang, \& Ha, 2016). Since privacy is a must-have element in e-Health services, its presence will affect the user satisfaction. On the other hand, its absence will negatively impact the user satisfaction. The study found a positive relationship between trust and satisfaction. According to Singh and Sirdeshmukh (2000), the trust-satisfaction relationship can be easily wrecked when a trust defect is committed. The authors stated that "a trust defect is something that disturbs consumers trust on the organization, its people, and its product". When customer trust is broken, they feel they are betrayed and that leads to dissatisfaction with the product/ service or organization.

Kim and Park (2012) highlighted this concept by building the proposition: "the negative effect (direct effect) of trust will surpass the positive effect of trust on satisfaction", that is distrust $\rightarrow$ disconfirmation $\rightarrow$ dissatisfaction. When the trust is gained, it not only satisfies consumers but also directly influences the repurchase intention, i.e., CUI. This finding reveals that trust will result in directly and indirectly affecting usage intention through satisfaction. The direct relationship among perceived service quality, satisfaction and usage intention is found to be significant. In the high-credence services such as electronic healthcare, providing the consistent quality of services will reduce the customers' uncertainty, which leads to satisfaction with the usage of services, which will directly affect CUI (Akter, D'Ambra, \& Ray, 2013). Social influence has a positive effect on the e-Health service usage, which is in line with previous studies (Oghuma, Libaque-Saenz, Wong, S\& Chang, 2015). This may be due to the fact that the higher the effects of social influence on users, the higher the likelihood of their CUI. According to De Veer, Peeters, Brabers et al. (2015), when the user expectations are satisfied, they influence their peers in using the services in mandatory context, such as e-Health, and later on they become more dependent on health services, which makes them more open to the influence of others.

\section{THEORETICAL AND PRACTICAL IMPLICATIONS}

In the concept of theory building, this study has made an attempt to integrate and extend the theories, which include the Expectation Confirmation Model (ECM) and the Technology Acceptance Model (TAM) by adding external constructs (privacy and security, trust, social influence and service quality), and implement them in the healthcare context. This method will create a reliable development theory that points to a significant addition to the up-coming literature on the continuous usage intention towards e-Health services.

The study findings have some important practical implications. For instance, they help service providers to understand the key factors of CUI of e-Health services. Besides, it is essential for a service provider to confirm that the provided services are a risk-free way to experiment and explore. Hospital customers tend to confirm their pre and post expectations of services. Therefore, it is es- 
sential for the hospitals to confirm patient expectations before delivering the service. If the delivered service does not meet patient expectations, they tend to discontinue the service. So, providers must confirm whether e-Health services satisfy the hospital customers or whether any changes are needed.

TAM and ECM key constructs, such as PEOU and $\mathrm{PU}$, were significant in terms of usage intentions. Therefore, it is important for service providers, service designers and developers to be light and helpful in providing or designing services, regardless of age, gender, qualification, and knowledge of technology. If the service provided is easy to use, then the availability of technology is easily adopted by all categories of people. As a result, this leads to positive word-of-mouth that pave the way for patient satisfaction, which really results in customer retention (Akter, D'Ambra, \& Ray, 2013). Also, service providers should focus more on enhancing social influence, as it is considered an important factor. According to Zhou (2014), this can be established by reinforcing "user's sense of membership and belonging and developing an influential, attractive and acceptable group norm to promote his or her post-adoption behavior".

In addition, to maintain and increase the patients' confidence and trust e-Health services, policy makers and service providers require to act by administering ethical information practices and guaranteeing health internet laws, legislations, and regulations. Health organization procedures and policies are required to promise the security, privacy and integrity of e-Health services; this would include data security and ethical issues related to e-health systems.
It is also necessary to mention the study limitations. First, the study findings have recognized social influence, trust, PSQ, and PPS as e-Health service characteristics with the background of extant literature. However, to portray a complete picture of e-Health services CUI, these four constructs are insufficient. Future study can include some other external variables to measure the usage intention. For example, Kim and Park (2012) have found that technological and individual characteristics are pertinent in accepting e-technologies. Similarly, Limayem, Hirt, and Cheung (2007) have recommended that 'habit' affects CUI in the e-service context. Second, for a short period of time, work was carried to identify user behavior, and conclusions were drawn based on cross-sectional data. As recommended by Bhattacherjee (2001), the respective significance of PU, satisfaction and confirmation in anticipating the CUI tend to vary, depending on specific situation and behavior. Therefore, the results may vary depending on cross-sectional data. To overcome this, it is necessary to conduct additional research with longitudinal studies in different time to make a comparison, which will provide a clear illustration of how associations between variables change over time. In addition, the integrated model does not take into account the moderating effect of demographics such as age and education level. Also, the current study was conducted in India, which has a collectivist culture, and applying to other culture requires further examination, and the culture does change the behavioral intentions of users (Oliveira, Thomas, Baptista, \& Campos, 2016). Future research may include culture and demographics, such as age and education level as moderators.

\section{CONCLUSION}

This study focuses on understanding the basic e-Health services continuance usage intention among patients by integrating the Expectation Confirmation Model (ECM) and the Technology Acceptance Model (TAM). Some external variables, such as social influence, perceived privacy and security, perceived service quality and trust, were included in the integrated models. After developing and testing the extended models, the study has found that confirmation and perceived easeof-use are the key factors that affect the continuance usage intention for basic e-Health services. Besides, the study concludes that other factors, such as perceived usefulness, satisfaction, trust, perceived service quality, perceived privacy and security and social influence, also affect the usage intention towards e-Health services. 


\section{AUTHOR CONTRIBUTIONS}

Conceptualization: Subhashree Natarajan.

Data curation: K Anil Kumar.

Formal analysis: Subhashree Natarajan.

Investigation: K Anil Kumar.

Methodology: Subhashree Natarajan.

Project administration: Subhashree Natarajan.

Software: K Anil Kumar.

Supervision: Subhashree Natarajan.

Validation: K Anil Kumar.

Writing - original draft: K Anil Kumar.

Writing - review \& editing: Subhashree Natarajan.

\section{REFERENCES}

1. Aggelidis, V. P., \& Chatzoglou, P. D. (2009). Using a modified technology acceptance model in hospitals. International journal of medical informatics, 78(2), 115-126. https://doi.org/10.1016/j. ijmedinf.2008.06.006

2. Akter, S., D'Ambra, J., \& Ray, P. (2013). Development and validation of an instrument to measure user perceived service quality of mHealth. Information and Management, 50(4), 181195. https://doi.org/10.1016/j. im.2013.03.001

3. Bhattacherjee, A. (2001). Understanding information systems continuance: an expectation-confirmation model. MIS Quarterly, 25(3), 351-370. Retrieved from https://www.jstor. org/stable/3250921

4. Boyce, M. B., Browne, J. P., \& Greenhalgh, J. (2014). The experiences of professionals with using information from patientreported outcome measures to improve the quality of healthcare: a systematic review of qualitative research. BMJ Quality and Safety, 23(6), 508-518. http://dx.doi. org/10.1136/bmjqs-2013-002524

5. Campanella, F., Serino, L., Mustilli, M., Crisci, A., \& D’Ambra, A. (2020). The evaluation of performance in the European public e-health services sector. Socio-Economic Planning Sciences, 100813. https://doi.org/10.1016/j. seps.2020.100813
6. Casaló, L. V., Flavián, C., \& Guinalíu, M. (2007). The role of security, privacy, usability and reputation in the development of online banking. Online Information Review, 31(5), 583-603. https://doi. org/10.1108/14684520710832315

7. Chang, H. H., \& Chen, S. W. (2009). Consumer perception of interface quality, security, and loyalty in electronic commerce. Information \& Management, 46(7), 411-417. https://doi.org/10.1016/j. im.2009.08.002

8. Chang, I. C., Liu, C. C., \& Chen, K. (2014). The effects of hedonic/ utilitarian expectations and social influence on continuance intention to play online games. Internet Research, 24(1), 21-45. https://doi.org/10.1108/IntR-022012-0025

9. Chang, M. Y., Pang, C., Tarn, J. M., Liu, T. S., \& Yen, D. C. (2015). Exploring user acceptance of an e-hospital service: An empirical study in Taiwan. Computer Standards and Interfaces, 38, 35-43. https://doi.org/10.1016/j. csi.2014.08.004

10. Chauhan, S., \& Jaiswal, M. (2017). A meta-analysis of e-health applications acceptance: Moderating impact of user types and e-health application types. Journal of Enterprise Information Management, 30(2), 295-319. https://doi.org/10.1108/JEIM-08 2015-0078
11. Chen, S. C., Liu, M. L., \& Lin, C. P. (2013). Integrating technology readiness into the expectationconfirmation model: An empirical study of mobile services. Cyberpsychology, Behavior, and Social Networking, 16(8), 604612. https://doi.org/10.1089/cyber.2012.0606

12. Cheng, Y. M. (2020). Drivers of physicians' satisfaction and continuance intention toward the cloud-based hospital information system. Kybernetes (ahead-of-print). https://doi. org/10.1108/K-09-2019-0628

13. Cho, J. (2016). The impact of postadoption beliefs on the continued use of health apps. International Journal of Medical Informatics, 87, 75-83. https://doi.org/10.1016/j. ijmedinf.2015.12.016

14. Cho, J., Quinlan, M., Park, D., \& Noh, G. (2014). Determinants of adoption of smartphone health apps among college students. American Journal of Health Behavior, 38(6), 360-370. https:// doi.org/10.5993/AJHB.38.6.8

15. Chuah, S. H. W., Rauschnabel, P. A., Krey, N., Nguyen, B., Ramayah, T., \& Lade, S. (2016). Wearable technologies: The role of usefulness and visibility in smartwatch adoption. Computers in Human Behavior, 65, 276284. https://doi.org/10.1016/j. chb.2016.07.047 
16. Davis, F. D., Bagozzi, R. P., \& Warshaw, P. R. (1989). User acceptance of computer technology: a comparison of two theoretical models. Management Science, 35(8), 982-1003. https:// doi.org/10.1287/mnsc.35.8.982

17. De Veer, A. J., Peeters, J. M., Brabers, A. E., Schellevis, F. G., Rademakers, J. J. J., \& Francke, A. L. (2015). Determinants of the intention to use e-Health by community dwelling older people. BMC Health Services Research, 15(1), 103. https://dx.doi.org/ 10.1186\%2Fs12913-015-0765-8

18. Emami, E., Kadoch, N., Homayounfar, S., Harnagea, H., Dupont, P., Giraudeau, N., \& Mariño, R. (2017). Patient satisfaction with E-Oral Health care in rural and remote settings: a systematic review protocol. Systematic reviews, 6(1), 174. https://dx.doi.org/10.1186/s13643017-0550-3

19. Fornell, C., \& Larcker, D. F. (1981). Structural equation models with unobservable variables and measurement error: Algebra and statistics. Journal of Marketing Research, 18(3), 382-388. https:// doi.org/10.2307/3150980

20. Furusa, S. S., \& Coleman, A. (2018). Factors influencing e-health implementation by medical doctors in public hospitals in Zimbabwe. South African Journal of Information Management, 20(1), 1-9. https:// doi.org/10.4102/sajim.v20i1.928

21. Gunther, E. (2001). What is e-Health? Journal of Medical Internet Research, 3(2), e20. http:// doi.org/10.2196/jmir.3.2.e20

22. Guo, Y., Hu, Y., Afzal, J., \& Bai, G. (2011). Using P2P technology to achieve eHealth interoperability (pp. 1-5). IEEE. https://doi.org/10.1109/ICSSSM.2011.5959430

23. Hair Jr, J. F., Hult, G. T. M., Ringle, C., \& Sarstedt, M. (2016). A primer on partial least squares structural equation modeling (PLS-SEM). Sage publications. Retrieved from https://www.amazon.com/PartialSquares-Structural-EquationModeling/dp/1452217440
24. Hair, J. F., Ringle, C. M., \& Sarstedt, M. (2013, March). Editorial Partial Least Squares Structural Equation Modeling: Rigorous Applications, Better Results and Higher Acceptance. Long Range Planning, 46(1-2), 1-12. Retrieved from https://ssrn.com/ abstract $=2233795$

25. Hair, J., Hollingsworth, C. L., Randolph, A. B., \& Chong, A. Y. L. (2017). An updated and expanded assessment of PLS-SEM in information systems research. Industrial Management and Data Systems, 117(3), 442-458. https:// doi.org/10.1108/IMDS-04-20160130

26. Hayashi, A., Chen, C., Ryan, T., \& Wu, J. (2020). The role of social presence and moderating role of computer self efficacy in predicting the continuance usage of e-learning systems. Journal of Information Systems Education, 15(2), 5. Retrieved from https:// aisel.aisnet.org/jise/vol15/iss2/5/

27. Holden, R. J., \& Karsh, B. T. (2010) The technology acceptance model: its past and its future in health care. Journal of Biomedical Informatics, 43(1), 159-172. https://doi. org/10.1016/j.jbi.2009.07.002

28. Hoque, M. R. (2016). An empirical study of mHealth adoption in a developing country: the moderating effect of gender concern. BMC Medical Informatics and Decision Making, 16(1), 51. https://doi.org/10.1186/s12911 016-0289-0

29. Hou, C. K. (2016). Understanding business intelligence system continuance intention: An empirical study of Taiwan's electronics industry. Information Development, 32(5), 1359-1371. https://doi. org/10.1177/0266666915599588

30. Hung, M. C., Hwang, H. G., \& Hsieh, T. C. (2007). An exploratory study on the continuance of mobile commerce: an extended expectation-confirmation model of information system use. International Journal of Mobile Communications, 5(4), 409-422. https://doi.org/10.1504/ IJMC.2007.012788
31. Joo, Y. J., Park, S., \& Shin, E. K. (2017). Students' expectation, satisfaction, and continuance intention to use digital textbooks. Computers in Human Behavior, 69, 83-90. https://doi.org/10.1016/j. chb.2016.12.025

32. Kim, J., \& Park, H. A. (2012). Development of a health information technology acceptance model using consumers' health behavior intention. Journal of Medical Internet Research, 14(5), e133. http://doi.org/10.2196/jmir.2143

33. Kline, R. B. (2011). Convergence of structural equation modeling and multilevel modeling. The SAGE Handbook of Innovation in Social Research Methods. http://doi. org/10.4135/9781446268261.n31

34. Kumar, K. A., \& Natarajan, S. (2019). Role of Trust and Privacy Concerns towards Usage of E-Health Service - An Extension of ExpectationConfirmation Model. Indian Journal of Public Health Research \& Development, 10(7), 339-349. http://dx.doi.org/10.5958/09765506.2019 .01590 .0

35. Lee, H. M., \& Chen, T. (2014). Perceived quality as a key antecedent in continuance intention on mobile commerce. International Journal of Electronic Commerce Studies, 5(2), 123142. http://dx.doi.org/10.7903/ ijecs. 1150

36. Limayem, M., Hirt, S. G., \& Cheung, C. M. (2007). How habit limits the predictive power of intention: The case of information systems continuance. MIS Quarterly, 31(4), 705-738. Retrieved from https://pdfs. semanticscholar.org/54aa/9bcd2 3445cc4fb3adeca9db8282570399 51f.pdf

37. Martínez-Caro, E., CegarraNavarro, J. G., \& Solano-Lorente, M. (2013). Understanding patient e-loyalty toward online health care services. Health Care Management Review, 38(1), 6170. http://dx.doi.org/10.1097/ HMR.0b013e31824b1c6b

38. Mathieson, K. (1991). Predicting user intentions: comparing the 
technology acceptance model with the theory of planned behavior. Information Systems Research, 2(3), 173-191. https://doi.org/10.1287/ isre.2.3.173

39. Melas, C. D., Zampetakis, L. A., Dimopoulou, A., \& Moustakis, V. (2011). Modeling the acceptance of clinical information systems among hospital medical staff: An extended TAM model. Journal of Biomedical Informatics, 44(4), 553-564. https:// doi.org/10.1016/j.jbi.2011.01.009

40. Mettler, T. (2012). Post-acceptance of electronic medical records: Evidence from a longitudinal field study. In Proceedings of the International Conference on Information Systems. Association for Information Systems. Retrieved from https://www.alexandria.unisg. $\mathrm{ch} / 218903 /$

41. Moore, G. C., \& Benbasat, I. (1991). Development of an instrument to measure the perceptions of adopting an information technology innovation. Information Systems Research, 2(3), 192-222. https://doi. org/10.1287/isre.2.3.192

42. Mou, J., \& Cohen, J. F. (2017). Trust and online consumer health service success: A longitudinal study. Information Development, 33(2), 169-189. https://doi. org/10.1177/0266666916642507

43. Mouakket, S. (2015). Factors influencing continuance intention to use social network sites: The Facebook case. Computers in Human Behavior, 53, 102110. https://doi.org/10.1016/j. chb.2015.06.045

44. Mutsai, T., \& Coleman, E. (2019). Towards an Understanding of Post-Adoption Usage Behaviors in the Context of M-Health Pregnancy Support Applications. In Proceedings of the South African Institute of Computer Scientists and Information Technologists 2019 (pp. 1-11). https://doi. org/10.1145/3351108.3351116

45. Oghuma, A. P., Libaque-Saenz, C. F., Wong, S. F., \& Chang, Y. (2016). An expectation-confirmation model of continuance intention to use mobile instant messaging. Telematics and Informatics, 33(1), 34-47. https://doi. org/10.1016/j.tele.2015.05.006
46. Oliveira, T., Thomas, M., Baptista, G., \& Campos, F. (2016). Mobile payment: Understanding the determinants of customer adoption and intention to recommend the technology. Computers in Human Behavior, 61, 404-414. https://doi. org/10.1016/j.chb.2016.03.030

47. Oliver, R. L. (1993). Cognitive, affective, and attribute bases of the satisfaction response. Journal of Consumer Research, 20(3), 418-430. https://doi.org/10.1086/209358

48. Parasuraman, A., Zeithaml, V. A., \& Berry, L. L. (1985). A conceptual model of service quality and its implications for future research. Journal of Marketing, 49(4), 41-50. Retrieved from https://www.jstor. org/stable/1251430

49. Paré, G., Trudel, M. C., \& Forget, P. (2014). Adoption, use, and impact of e-booking in private medical practices: mixed-methods evaluation of a two-year showcase project in Canada. JMIR Medical Informatics, 2(2), e24. https://doi. org/10.2196/medinform.3669

50. Premkumar, G., \& Bhattacherjee, A. (2008). Explaining information technology usage: A test of competing models. Omega, 36(1), 64-75. Retrieved from https:// ideas.repec.org/a/eee/jomega/ v36y2008ilp64-75.html

51. Ramprasad, C., Tamariz, L., Garcia-Barcena, J., Nemeth, Z., \& Palacio, A. (2019). The use of tablet technology by older adults in health care settings - is it effective and satisfying? A systematic review and meta analysis. Clinical Gerontologist, 42(1), 17-26. https://doi.org/10.1080 /07317115.2017.1322162

52. Sarstedt, M., Ringle, C. M., \& Hair, J. F. (2017). Partial least squares structural equation modeling. Handbook of market research, 1-40. https://doi.org/10.1007/978-3-31905542-8_15-1

53. Singh, J., \& Sirdeshmukh, D. (2000). Agency and trust mechanisms in consumer satisfaction and loyalty judgments. Journal of the Academy of Marketing Science, 28(1), 150-167. https://doi. org/10.1177/0092070300281014

54. Susanto, A., Chang, Y., \& Ha, Y. (2016). Determinants of continuance intention to use the smartphone banking services: an extension to the expectationconfirmation model. Industrial Management and Data Systems, 116(3), 508-525. https://doi. org/10.1108/IMDS-05-2015-0195

55. Thong, J. Y., Hong, S. J., \& Tam, K. Y. (2006). The effects of postadoption beliefs on the expectationconfirmation model for information technology continuance. International Journal of HumanComputer Studies, 64(9), 799-810. Retrieved from http://hdl.handle. net/1783.1/37812

56. Varshney, U. (2009). Pervasive healthcare computing: $E M R / E H R$, wireless and health monitoring. Springer Science \& Business Media.

57. Venkatesh, V., Thong, J. Y., \& Xu, X. (2012). Consumer acceptance and use of information technology: extending the unified theory of acceptance and use of technology. MIS Quarterly, 36(1), 157-178. Retrieved from https://www.jstor. org/stable/41410412

58. Wang, H. Y. (2016). Predicting customers' intentions to check in on Facebook while patronizing hospitality firms. Service Business, 10(1), 201-222. http://dx.doi.org 10.1007\%2Fs11628-014-0265-7

59. Wang, H., Liu, S., Gao, B., \& Zhang, J. (2020, January). Service Failure and Consumers' Satisfaction with the Healthcare Industry: Moderating Role of Recommendation. In Proceedings of the 53rd Hawaii International Conference on System Sciences. Retrieved from https://scholarspace.manoa.hawaii.edu/bitstream/10125/64144/0324.pdf

60. Zhang, H., Lu, Y., Gupta, S., \& Gao, P. (2015). Understanding group-buying websites continuance: An extension of expectation confirmation model. Internet Research, 25(5), 767-793. https://doi. org/10.1108/IntR-05-2014-0127

61. Zhou, T., \& Li, H. (2014).

Understanding mobile SNS continuance usage in China from the perspectives of social influence and privacy concern. Computers in Human Behavior, 37, $283-$ 289. https://doi.org/10.1016/j. chb.2014.05.008 